\title{
EU Energy Policy: A Socio-Energy Perspective for an Inclusive Energy Transition
}

\author{
Anna Mengolini and Marcelo Masera
}

\begin{abstract}
This chapter presents the evolution of EU energy policy, examining how concepts of inclusiveness and justice in energy have been progressively included in relevant energy policy documents. It discusses how EU energy policy has evolved to acknowledge the importance of the individual as well as the collective dimension of energy for an inclusive green transition. Recognizing the challenges linked to the translation of these concepts into concrete actions, the chapter elaborates a socio-energy system approach that can help in making visible important aspects of the energy transition that would go unrecognized in other analytical approaches that focus mainly on the technological side. There is an increasing awareness that the European Green Deal and other political initiatives for a sustainable future require not only technological change but also careful attention to the social implications of the transition. The chapter applies the proposed approach to smart metering technologies, discussing how the technology-centric view of the energy system is framed around the average consumer or early-adopter, leaving vulnerable groups and those living in energy poverty underrepresented. A socio-energy approach also challenges the predominant use of purely quantitative results such as energy or cost savings to evaluate the successfulness of initiatives tackling inclusiveness and fairness (e.g. energy poverty). Social outcomes of energy policy choices and technology arrangements need to be better investigated and accompanied by innovative ways to measure their success. The proposed socio-energy approach offers a way of including wider societal implications of the energy transition in the design of energy policies and in their implementation.
\end{abstract}

\section{Introduction}

The European Union (EU) energy policy recognizes the central role of energy consumers "in achieving the flexibility necessary to adapt the electricity system to variable and distributed renewable electricity generation" (Directive (EU) 2019/944,

\footnotetext{
A. Mengolini $(\varangle) \cdot$ M. Masera

Joint Research Centre of the European Commission, Petten, The Netherlands

e-mail: anna.mengolini@ec.europa.eu

(C) The Author(s) 2021

M. P. C. Weijnen et al. (eds.), Shaping an Inclusive Energy Transition,

https://doi.org/10.1007/978-3-030-74586-8_7
} 
2019). Empowering and providing consumers with the tools to participate more actively in the energy market, will help to achieve the EU renewable energy targets ${ }^{1}$ and enable EU citizens to benefit from the internal market for electricity.

The European consumer policy has been based on the assumption of rationalacting consumers who tend to maximize their profits and has its roots in the information paradigm; this suggests that consumers are able, willing and competent to deal with the information provided and to take informed rational decisions (Micklitz et al., 2011). In this regard, consumers are mostly viewed as individuals and the collective dimension is largely set aside. However, recent energy policy documents present a shift towards a closer attention to the collective dimension of energy. The 2019 Clean Energy for All Europeans, while reinforcing the central role of EU citizens in the energy transition, also strengthened concepts as consumers' rights, energy poverty and vulnerable consumers, and introduced the notion of "citizen energy communities". ${ }^{2}$ This articulated set of positions recognizes the importance of the collective dimension of energy production and use and how this could "help fight energy poverty" (Directive (EU) 2019/944, 2019) and thus strive towards a more inclusive energy transition.

The shift from generation in large central installations towards decentralized production of electricity from renewable sources is transforming the European Union's energy system, requiring the development of new strategies for handling a more decentralized system composed of heterogeneous social and technological actors motivated by different interests and agendas (Mengolini, 2017). In recent years, technological innovation and the decreasing cost of technology have made new forms of consumer participation in energy production and management more accessible (Council of European Energy Regulators, 2019). Consumers have started to produce, store and consume their own energy and are able to support the operation of power grids and energy market by changing their load patterns.

EU investments in smart electricity systems research and innovation have been steadily increasing in the last ten years (Gangale et al., 2017), however these efforts have mainly focused on the testing of enabling technological solutions without specifically addressing the needs of vulnerable consumers and the wider societal aspects of an inclusive energy transition (e.g. energy poverty) (Gangale \& Mengolini, 2019). Indeed, the growing interest at policy level for an inclusive energy transition has not yet been reflected in the research and innovation initiatives carried out with EU financial support and in the implementation of current energy policies (e.g., smart metering roll out). Research and innovation $(\mathrm{R} \& \mathrm{I})$ projects can play a pivotal role to address and investigate the technological, regulatory, economic and social challenges of the collective dimension of energy and to speed up the transition to an inclusive energy system with individuals and communities at its heart (Gangale et al., 2020; Gangale \& Mengolini, 2019; Mengolini et al., 2016). To investigate these social challenges, the shift should be towards a socio-energy approach that would make visible

\footnotetext{
${ }^{1}$ At least $32 \%$ of energy from renewable sources in the Union's gross final consumption of energy in 2030 (Directive (EU) 2018/2001, 2018).

${ }^{2}$ Article 12 (Directive (EU) 2019/944, 2019).
} 
important aspects of the energy transition that go unrecognized in other analytical approaches that focus mainly on the technological and market sides.

This chapter proceeds by presenting how issues of consumer protection, citizen engagement and inclusiveness have been receiving increasing attention in EU energy policy and how EU energy policy has evolved to recognize the importance of the individual as well as the collective dimension of energy for an inclusive energy transition (Section "The Social Dimensions of EU Energy Policy: The Role of Consumers and Communities"). Section "A Framework for an Inclusive Energy Transition" introduces a socio-energy approach to the energy transition with the aim of improving the understanding of social drivers, dynamics and outcomes of energy systems change. Section "A Socio-Energy System Approach to Smart Metering Infrastructure" applies the socio-energy approach to smart metering technologies, Section "Concluding Remarks" offers some reflections and conclusions.

\section{The Social Dimensions of EU Energy Policy: The Role of Consumers and Communities}

\section{First Steps in the EU Internal Energy Market}

Progress towards a common energy policy was limited in the first decades of European integration. The progress made with the first legislative package ${ }^{3}$ was mainly based on internal market and environmental regulations of the EU Treaties. Neither the Treaty of Amsterdam (1999) nor the Treaty of Nice (2003) brought major progress for a common energy policy.

Major advances came only in 2007 when EU heads of state and government endorsed the first EU energy action plan that resulted in the Commission's Communication An energy policy for Europe (COM(2007) 1, 2007) that laid down the three major challenges for European energy policy: sustainability, security of supply and competitiveness. The action plan was followed by changes in the EU legislation. The Treaty of Lisbon (signed on 13 December 2007) added a new part on energy to the Treaty on the Functioning of the European Union (TFEU), namely article 194 in Title XXI of the consolidated TFEU. The insertion of the title on energy in the Lisbon Treaty suggests a European Union's push toward a harmonized common energy policy "in a spirit of solidarity between Member States" (article 194 in (TFEU, 2012)), and represents an important step forward towards a common energy policy, explicitly promoting energy efficiency and energy savings as key elements.

\footnotetext{
${ }^{3}$ Directive concerning common rules for the internal market in electricity (Directive 96/92/EC, 1996) and Directive on common rules for the internal market in natural gas (Directive 98/30/EC, 1998).
} 
An array of new legislation followed, with the 2009 Third Energy Package representing a further step towards the improvement of the functioning of the internal energy market. It established that all EU citizens have the right to have their homes connected to energy networks and to freely choose any supplier of gas or electricity offering services in their area. Moreover, the package urged to recognise that consumers have the right to access accurate information on their consumption data and associated electricity prices. This information on the electricity costs should be provided frequently enough in order to create incentives for energy savings and behavioural change and is facilitated by the deployment of smart metering infrastructure. Such information provision could also create innovative services to effectively enable active participation of consumers in the electricity supply market. Furthermore, the third legislative package prescribes the EU Member States to define the concept of vulnerable consumers at the national level and to adopt measures to protect such consumers and to address energy poverty.

To drive forward the consumer-related issues that were included in the Third Energy Package, in 2008 the European Commission (EC) established the Citizens' Energy Forum (also known as the London Forum) as a regulatory platform to help deliver competitive, energy efficient and fair retail markets for consumers. The Citizens' Energy Forum brings together national consumer organisations, industry representatives, national regulators and government authorities to discuss key issues such as approaches to protecting vulnerable consumers, price transparency, switching energy suppliers, user-friendly billing, and smart metering. Issues of energy poverty, vulnerable consumers and consumer's protection were additionally examined in a Commission Staff Working Paper, An energy policy for consumers (SEC(2010) 1407, 2010).

To further explore the concept of vulnerable consumers and support Member States (MSs) in the implementation of the Third Energy Package, the EC established in 2011 the Vulnerable Consumer Working Group.

\section{Towards a Common Energy Union Strategy: Energy Consumer at the Centre}

A major step towards the definition of a common EU energy strategy came in 2015 with the Energy Union Package-Framework for a Resilient Energy Union with a Forward Looking Climate Change Policy. The Energy Union strategy (COM(2015) $80,2015)$ placed citizens at its core and recognized that by taking ownership of

\footnotetext{
${ }^{4}$ Directive on the promotion of the use of energy from renewable sources (Directive 2009/28/EC, 2009), Directive concerning common rules for the internal market in electricity, (Directive 2009/72/EC, 2009), Regulation on conditions for access to the network for cross-border exchanges in electricity (Regulation (EC) No. 714/2009, 2009), Regulation on conditions for access to the natural gas transmission networks (Regulation (EC) No. 715/2009, 2009), Regulation establishing an Agency for the Cooperation of Energy Regulators, (Regulation (EC) No. 713/2009, 2009).
} 
the opportunities allowed by the energy transition, they can "benefit from new technologies to reduce their bills, participate actively in the market" (COM(2015) 80, 2015 , p. 2) and contribute to an energy transition where vulnerable consumers are protected. The strategy set out, in five interrelated policy dimensions, the goals of an energy union: energy security, solidarity and trust; a fully integrated European energy market; energy efficiency contributing to moderation of demand; decarbonising the economy, and research, innovation and competitiveness.

The ensuing Commission's Communication “Delivering a New Deal for Energy Consumers" $(\operatorname{COM}(2015) 339,2015)$ further clarifies the role of the consumer in the energy transition. It recognises that the combination of decentralized generation with storage options and demand side flexibility "can further enable consumers to become their own suppliers and managers for (a part of) their energy needs, becoming producers and consumers and reduce their energy bills" (COM(2015) 339,2015 , p. 6), thus introducing the concept of consumer-producer, also termed 'prosumer'.

\section{From Consumers to Citizens' Joint Actions: The Collective Dimension of EU Energy Policy}

While the New Deal for the Energy Consumers recognizes that consumers increasingly participate in collective schemes and community initiatives, "to better manage their energy consumption", it is only with the Clean Energy for All Europeans Communication (COM(2016) 860, 2016) that the collective dimension of energy is fully recognized. The Clean Energy for all Europeans Package (CEP) argues that energy transition creates new opportunities and challenges for market participants, allowing, through technological development, for new forms of consumer participation and cross-border cooperation. It further elaborates the central role that jointly acting consumers can play in the energy transition. The implementation of CEP proposals into CEP legislative acts was finalised in 2019 and it includes eight legislative acts. ${ }^{5}$ The CEP establishes a legislative framework where "active customer" (definition that also includes "a group of jointly acting final customers")

\footnotetext{
${ }^{5}$ Clean Energy for all Europeans Package legislative acts: Energy performance in buildings (Directive (EU) 2018/844, 2018), Renewable energy directive (Directive (EU) 2018/2001, 2018), Energy efficiency Directive (Directive (EU) 2018/2002, 2018), Regulation on the Governance of the Energy Union (Regulation (EU) 2018/1999, 2018), Regulation on the internal market for electricity (Regulation (EU) 2019/943, 2019), Electricity Directive (Directive (EU) 2019/944, 2019), Regulation on risk-preparedness in the electricity sector (Regulation (EU) 2019/941, 2019), Regulation establishing a European Union Agency for the Cooperation of Energy Regulators (Regulation (EU) 2019/942, 2019).

${ }^{6}$ (Directive (EU) 2019/944, 2019), article 2, point 8: 'active customer' means a final customer, or a group of jointly acting final customers, who consumes or stores electricity generated within its premises located within confined boundaries or, where permitted by a Member State, within other premises, or who sells self-generated electricity or participates in flexibility or energy efficiency
} 
and "jointly acting renewable self-consumers", 7 have more opportunities to get involved in the energy transition. Communities and individuals are given the right to produce, store, consume and sell their own energy. The Electricity Directive (Directive (EU) 2019/944, 2019) and Renewable Energy Directive (Directive 2009/28/EC, 2009) provide the definitions of "citizen energy community"8 and "renewable energy community" "which are both formulated as particular ways to organise collective actions around a specific energy-related activity through the community organized as legal entity. The focus shifts from the individual consumer acting in isolation to the collective dimension of energy and to how this can contribute to a more inclusive energy transition. Indeed, the Electricity Directive highlights that community-level energy represents an inclusive option for all consumers "to have a direct stake in producing, consuming and or sharing energy between each other" (recital 43 of (Directive (EU) 2019/944, 2019)) and in fighting energy poverty through reduced consumption and lower supply tariffs. Energy community initiatives directly involve and engage with consumers and therefore can be best suited to "... facilitating the uptake of new technologies and consumption patterns, including smart distribution grids and demand response, in an integrated manner" (recital 43 of (Directive (EU) 2019/944, 2019)). The Directive further highlights that "Energy services are fundamental to safeguarding the well-being of the Union citizens. Adequate warmth, cooling and lighting, and energy to power appliances are essential services to guarantee a decent standard of living and citizens' health. Furthermore, access to those energy services enables Union citizens to fulfil their potential and enhances social inclusion" (recital 59 of (Directive (EU) 2019/944, 2019)). That energy transition must be fair and socially acceptable for all is confirmed in the Fourth Report on the State of the Energy Union: its social implications must be part of the policy process from the outset and not simply be an afterthought (COM(2019) 175, 2019). In 2018,

schemes, provided that those activities do not constitute its primary commercial or professional activity.

${ }^{7}$ (Directive (EU) 2018/2001, 2018), article 2, point 15: 'jointly acting renewables self-consumers' means a group of at least two jointly acting renewables self-consumers in accordance with point (14) who are located in the same building or multi-apartment block.

8 'citizen energy community' means a legal entity that: (a) is based on voluntary and open participation and is effectively controlled by members or shareholders that are natural persons, local authorities, including municipalities, or small enterprises; (b) has for its primary purpose to provide environmental, economic or social community benefits to its members or shareholders or to the local areas where it operates rather than to generate financial profits; and (c) may engage in generation, including from renewable sources, distribution, supply, consumption, aggregation, energy storage, energy efficiency services or charging services for electric vehicles or provide other energy services to its members or shareholders. (Directive (EU) 2019/944, 2019), article 2, point 11.

9 'renewable energy community' means a legal entity: (a) which, in accordance with the applicable national law, is based on open and voluntary participation, is autonomous, and is effectively controlled by shareholders or members that are located in the proximity of the renewable energy projects that are owned and developed by that legal entity; (b) the shareholders or members of which are natural persons, SMEs or local authorities, including municipalities; (c) the primary purpose of which is to provide environmental, economic or social community benefits for its shareholders or members or for the local areas where it operates, rather than financial profits. (Directive (EU) 2018/2001, 2018), article 2, point 16. 
the EC, as part of its policy efforts to address energy poverty across EU countries, launched the EU Energy Poverty Observatory (EPOV) with the mission to engender transformational change in knowledge about the extent of energy poverty in Europe, and innovative policies and practices to combat it.

Along the same line, the recent European Green Deal presents a forward-looking strategy establishing the goal that no energy consumer should be left-behind. It emphasises the involvement of "local communities in working towards a more sustainable future" and the need to further "empower regional and local communities, including energy communities" (COM(2019) 640, 2019, pp. 18, 21). It also advocates for a socially just transition where the risk of energy poverty must be addressed and citizens and workers most vulnerable to the energy transition must be protected.

\section{The Twin EU Energy and Digital Transitions}

In the communication Shaping Europe's digital future the EC recognizes that the twin challenge of a green and digital transformation has to happen together in order for Europe to lead the transition to a healthy planet and a new digital world (COM(2020) $67,2020)$. The energy sector has been an early adopter of digital technologies, using them to facilitate grid management and operation. It is argued that in the next decades digital technologies will enable more connected, intelligent, efficient, reliable and sustainable energy systems (IEA, 2017). To this end, digitalization of the energy sector should be adopted along the whole value chain, from production, to distribution, consumption and management of energy. For example, smart metering systems, by providing feedback on electricity consumption, enable the consumers to monitor and manage their energy use. However, smart metering technologies implementation (and digital technologies in general) should be accompanied by an assessment of the associated societal implications to guarantee an early identification of the challenges and opportunities that the use of digital technologies and other innovative solutions can present for EU consumers' living conditions. It is therefore of paramount importance to ensure that digital development policies avoid amplifying existing inequalities and leaving vulnerable groups behind, such as those on low incomes, tenants living in multi-storey buildings and those who are digitally excluded. This requires a socio-energy approach to the energy transition to guarantee a comprehensive view of its social dimension.

\section{The Social Dimension of EU: Energy as a Fundamental Right}

The reflection paper on The Social Dimension of Europe warns that "economic and technological change may result in new patterns of inequality, with a persistent risk of poverty coinciding with new forms of exclusion". It calls for a cohesive society 
that guarantees an inclusive growth and social justice (COM(2017) 206, 2017). The reflection paper paved the way for the publication of the European Pillar of Social Rights (European Union, 2017) that set out 20 key principles to support fair and wellfunctioning labour markets and welfare systems. In particular, one of the key principles is access to essential services; it recognizes that everyone has the right to access essential services of good quality, including water, sanitation, energy, transport, financial services and digital communications. Support for access to such services shall be available for those in need. Already in 2012, the Charter of Fundamental Rights of the EU recognized (Chapter IV, Solidarity) access to services of economic interests and consumer protection as fundamental rights (European Union, 2012). More recently, the reflection paper Towards a sustainable Europe by 2030 (COM(2019)22, 2019) states that a transition to a low-carbon, climate-neutral, resource-efficient and biodiverse economy needs to be innovative, green, inclusive and socially just, leaving no one behind and in full compliance with the United Nations 2030 Agenda and the 17 Sustainable Development Goals.

The COVID-19 crisis came at a time when EU climate and energy policies were experiencing a new thrust with overall policy frameworks targeting carbon neutrality (e.g. the European Green Deal) and countries dealing with the implementation of climate and energy law frameworks at national level. The crisis has shown that the right to energy and energy services are essential ingredients for an inclusive energy transition (ENGAGER, 2020) and that, therefore, these new policy frameworks should be defended given their importance for structural and societal beneficial changes of the energy system (Steffen et al., 2020). A just transition that safeguards social inclusiveness and enables a fair recovery of the EU economy after COVID-19 becomes an imperative in order to maintain the political acceptability of a climate neutrality goal (IEA, 2020). In this respect, the Recovery Plan Communication Europe's moment: Repair and Prepare for the Next Generation advocates the need for a fair and inclusive recovery that must address disparities and inequalities either exposed or exacerbated in the crisis $((\operatorname{COM}(2020) 456,2020)$ while proceeding with the twin green and digital transitions toward a fairer and more resilient society.

\section{The Way Forward: Energy Democracy and Energy Justice}

The evolution of the main EU energy policy documents and initiatives is summarized in Fig. 1. With the onset of the Energy Union Package there has been an acceleration in the number of documents addressing the social implications of the energy transition. Although concepts of energy justice and energy democracy are not as such included in the EU policy documents analysed, one can argue that they are at the core of the EU (energy) transition. Energy justice has recently emerged as a new cross-cutting social science research agenda seeking to apply justice principles to the energy field by questioning "the ways in which benefits and ills are distributed, remediated and victims are recognized" (Jenkins et al., 2016). Energy democracy, on the other hand, aims at greater citizen involvement and control in the energy systems (van Veelen 


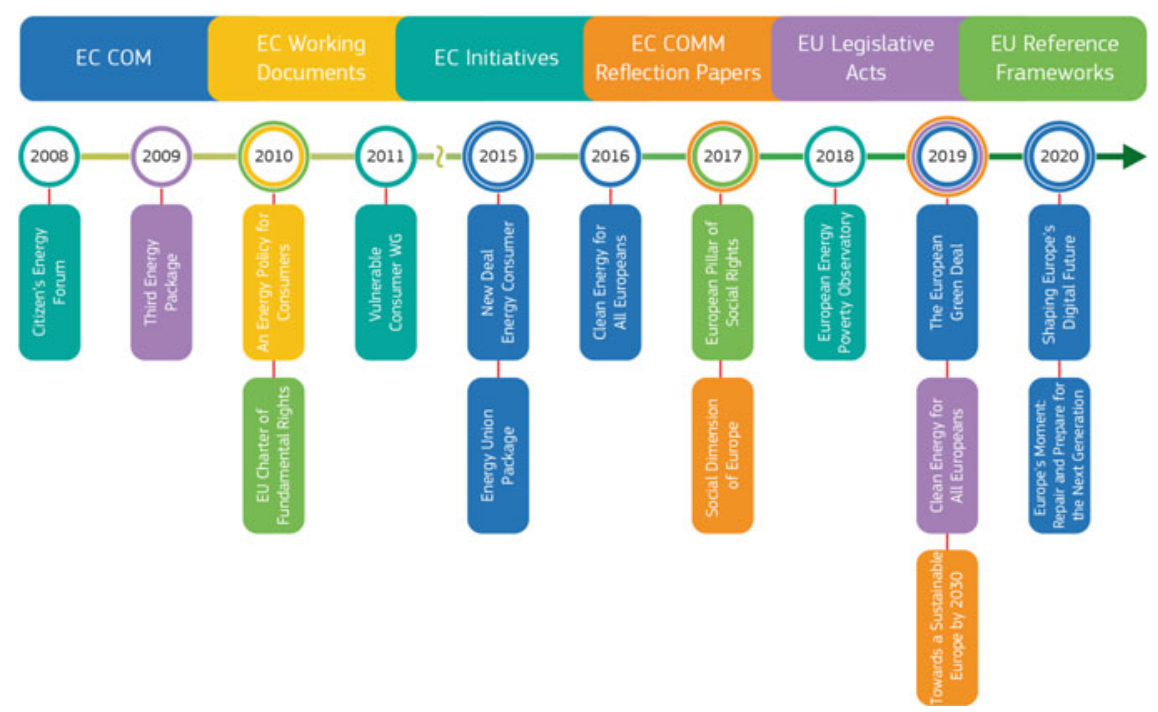

Fig. 1 EU Energy policy key documents; EC COMM: non-binding legal instruments that include policy evaluations, commentary or explanations of action-programmes or brief outlines on future policies or arrangements concerning details of current policy; EC working documents: they are geared towards providing information on certain policies, programmes and legislative proposals or in support of current policies; EC working groups: working groups whose mandate is to support Commission's work on specific topics; EC COMM reflection papers: documents outlining the view of the EC on key topics that will define the coming years; EU legislative acts: legally-binding acts of the European Union, such as directives and regulations; $E U$ reference frameworks for social rights: framework jointly proclaimed by the European Parliament, the Council and the Commission

\& van der Horst, 2018). Energy justice and energy democracy are closely related and can be considered a translation of the democracy principle and the rule of law to the energy field that are the foundations of the European Union and are at the service of a just society (Vitéz \& Lavrijssen, 2020). The recognition of the collective dimension of energy enhances the role of the consumers in the transition of the energy system where they assume an active role, not only as consumers or users, but also as 'energy citizens' actively involved in shaping policies in the area of energy (Vesnic-Alujevic et al., 2016). Greater citizen involvement is at the heart of the energy democracy principle (van Veelen \& van der Horst, 2018; Vitéz \& Lavrijssen, 2020). As Devine-Wright suggests, 'energy citizens' is an alternative view of the public where "the potential for actions is framed by notions of equitable rights and responsibilities across society for dealing with the consequences of energy consumption" (Devine-Wright, 2007, p. 71). Energy citizenship contrasts the social and psychological detachment of the public from energy systems that is embedded within centralized systems. In contrast to the past view of energy consumer, for whom energy was simply a good to be expended in pursuit of personal goals, the energy citizen engages with energy as a meaningful part of their practices and is better understood in a community context. This view of an EU energy citizen with 
equitable rights and responsibilities in shaping and defining the energy transition should be at the core of reliable and transparent EU energy governance.

\section{A Framework for an Inclusive Energy Transition}

\section{A Socio-Energy Approach: The Dimensions}

While policies have recurrently indicated the ambition to take into consideration socio-technical issues, the translation of those aspirations into concrete actions is particularly challenging. A case in point is the Electricity Directive (Directive (EU) 2019/944, 2019), which highlights the need for an integrated approach to energy transition with no further details on how this can be achieved. Energy policy is indeed a problem of "socio-energy system design" (Miller et al., 2015). A more comprehensive approach should enable an active participation of society in the political discussions and in the elaboration and assessment of the related programmes and projects. There is an increasing awareness that the European Green Deal and other political initiatives for a sustainable future require not only technological change but also changes in consumption and social practices (Strand et al., 2021). In this context we argue in favour of a socio-energy system approach (Miller et al., 2015) that makes visible important aspects of the energy transition that go unrecognized in other analytical approaches that focus on the technological side. In applying this perspective, one should investigate the social processes that stimulate and manage the energy transformation, inquiring about the choices and behaviours of the social agents involved in the energy transition (business managers, policy makers, consumers...); furthermore, one should investigate the social changes that accompany shifts in energy technologies and that reshape social practices, values, relationships and institutions and the social outcomes that flow from the operation and organization of new energy systems.

In this light, and inspired by (Miller et al., 2013), we propose a framework for the deliberation of the social characteristics of energy policies that takes into consideration three dimensions: social processes, social changes and social outcomes.

\section{Social Processes}

Social processes are represented by the actions and decision making processes of various social actors. The energy transformation is the result of series of choices made by these actors (e.g. citizens, energy companies, public institutions, energy consumers, industrial users, etc.)

One fundamental social process in the energy transition is the communication from public authorities and energy operators to consumers regarding their plans 
for the deployment of assets and regulation of the retail market. The need to have structured dialogues with all stakeholders is a stronghold of all climate and energy policies. These dialogues might moderate the inevitable asymmetric nature of information access and agency capacity in any given society. The information about the issues at hand is recognised as depending on a clear political lead, and as the main enabler for the engagement of the citizens concerned (COM(2015) 339, 2015). One clear case in point is provided by the German policy for the so-called Energiewende (BMWI-BMU, 2010). It foresaw the participation of societal actors (such as citizens at large, but also NGOs, think-tanks, and even foundations linked to political parties) at different stages, looking for broad social consensus. For instance, there was, since the coming into force of the Renewable Energy Sources Act (BMWI, Renewable Energy Sources, 2017), wide dissemination of information on the feed-in tariffs that would support the installation of renewable energy generation by households (e.g. PV panels). The German Federal Ministry for Economic Affairs and Energy set up a web portal for all information regarding the Energiewende, ${ }^{10}$ and produced the Energiewende Direkt newsletter that provides facts and background information on renewable energy in Germany. ${ }^{11}$ On the other hand, there were criticisms on the lack of transparency on the parallel increase in electricity prices resulting from the feed-in tariffs. This increment has been of $22 \%$ of the average monthly electricity bill in 2016 (Ecologic Institute, 2016). In addition, the rules governing the payment for renewable power were revised, triggering uncertainty for investments made by citizens, as these are more exposed to volatility in the market.

\section{Social Changes}

The link between the social actors and the energy resource is mediated by a wide set of instruments of very different nature: from smart meters and new billing arrangements, to demand side management and differentiated tariffs, from the setting of energy communities to self-consumption. In this light, social changes are concerned with modifications in the appropriation, acceptance and use by the social actors of the new energy technologies, systems, services and market structures. Social changes are for example modifications in behaviours, especially regarding the adoption of technologies, the investment in devices, the acceptance of regulations and measures, and the variation of energy consumption patterns (Steg et al., 2018). In the last years there have been numerous studies on these behavioural changes, including the indirect and spill over effects of those changes affecting other activities relevant to energy, climate and the environment. All these social changes might be unwanted, happening as the mere result of the advancement of policy, technology and market factors, or be planned and intended as the product of an institutionalised socio-technical regime, established by authorities or operators. This distinction is fundamental for distinguishing and assessing different social dynamics.

\footnotetext{
${ }^{10}$ www.bmwi.de/EN/Topics/Energy/energytransition.html.

${ }^{11}$ https://www.bmwi-energiewende.de/EWD/Navigation/EN/Home/home.html.
} 


\section{Social Outcomes}

Social outcomes flow from the operation of the emerging energy systems and may create or reinforce existing inequalities. The complex interactions of policies, technologies, and economic and social elements will oftentimes generate unforeseeable and undesirable consequences. Some of these consequences can emerge in a short period and might be easily adjusted as required, but others will cause consequences only materialising in the mid-term, so ingrained that they might be difficult to be remedied (i.e. subsidies to investment in households that expand economic disparities). The criteria used for evaluating those outcomes might change with time (e.g. how to judge the fairness of energy prices). Central to the evaluation of outcomes is the existence of multiple and contrasting standards for judging what is acceptable, and of multiple objectives that might be in contradiction with each other (e.g. energy security vs energy sustainability). From this it follows that there is no way for optimising the energy transition, and that all major decisions with society-wide impacts will require social debate and political ruling.

\section{Critical Aspects of the Energy Transformation}

These three dimensions of a socio-energy approach intersect with three critical aspects of the energy transformation that a socio-energy perspective should address: infrastructure, knowledge and governance (Miller et al., 2013).

As part of the socio-technical assessment one should examine how the decisions regarding energy infrastructures, which are relatively hidden from public scrutiny, impact social arrangements. Whose knowledge counts? Who knows about energy systems? How and what do they know? What governance should be put in place to implement an inclusive energy transition that will not generate negative social impacts? To answer these questions we need a socio-energy system view of the energy transition that makes all relevant aspects visible so they can be taken into due account in the governance mechanisms.

The various social actors have different levels of insight and awareness regarding the energy system. As an infrastructure, the energy system underpins and determines the social use of energy. How much of that infrastructure is perceptible by the general public? People's perceptions of all elements in the value chain are often inaccurate, from the energy source to energy consumption of devices, from the impact of technologies to the role of the energy grids, from the factors affecting the price of energy to the externalities. The situation of deficiency in perception can be better managed in local projects, where the involvement of policy makers and practitioners with the civil society actors can be fostered. Several examples demonstrate how participatory processes can help on this front (ENLARGE, 2018). However, what would be feasible at the local level, is daunting when the number of actors dramatically increases such as in vast regions. Some analytic frameworks defend for this reason a community setting for debating energy developments, but it is apparent that not 
all energy issues (and mainly those relating to the transmission/transport and wholesale market) can be reduced to the local community level. This can be a source of conflicts, and merit special consideration in the governance arrangement (Brisbois, 2020; Veuma \& Bauknecht, 2019).

The level of influence on the decisions affecting the energy system will be determined by the knowledge of its structure and functioning. It is implausible to request all citizens to have a full understanding of energy systems, but it is relevant to reflect on the knowledge that might be needed by the general public.

The distance between scientific and technical knowledge on the various topics of interest, and the basic knowledge that the population at large might acquire needs to be acknowledged. In a world of rapidly changing industrial and research products, accompanied by a multitude of assessments claiming disparate and often contradictory results, it is hard to determine a common and solid epistemic basic reference and to organise social processes based on pure technical evidence. The presentation of the same energy choices is frequently obfuscated by knowledge mixed with ideological positions and political disputes. There is no direct and unequivocal link between more knowledge and behavioural choices (Frederiks et al., 2015; Steg et al., 2015), but knowledge affects the awareness on the matters at issue and the understanding of the potential choices by individuals and social groups.

Finally, a socio-energy approach needs governance and justice (Mundaca et al., 2018) (i.e. how authorities at different levels define the rules, regulations, institutions and administrative instruments affecting the infrastructure investments, the market and the rights of the social actors). As the roles of the various actors change, justice in the social processes, social changes and social outcomes is seen as a crucial factor, with participatory approaches as theme of active research (Halbe et al., 2020). As the energy infrastructure and market are organised at different planes, multi-level governance is necessary. Participative governance is recognised as central for getting the engagement of the citizens. Several open questions remain on which participatory processes can be effective beyond local communities. The extension of participatory approaches beyond this appears to be challenging.

\section{A Socio-Energy System Approach to Smart Metering Infrastructure}

The assumption of the EU energy legislation is that consumers and energy communities will be active players in the energy markets, producing, consuming, selling and storing energy. There is a wealth of research that has studied consumers engagement in energy (Cseres, 2018; Gangale et al., 2013; Lavrijssen, 2014, 2017); however, not all consumers are the same. There is the need to look not only at an 'average' consumer, but also at different consumer groups in order to address the risk that certain consumers can be excluded from or be impacted negatively by the energy transition (BEUC, 2019). With this in mind, we apply the socio-energy approach discussed in the previous section to smart metering technologies. 
The deployment of smart metering systems in Europe is driven by EU legislation that views smart metering infrastructure as a tool to both enhance competition in retail markets and foster energy efficiency. Moreover, smart metering technologies are considered as key enablers to realising the full potential of renewable energy integration and for the active involvement of consumers and communities in the energy transition (Bugden \& Stedman, 2019). However, the potential for smart metering systems per se to trigger consumer engagement and behavioural changes is rather limited. The information on consumption provided by smart meters needs to be accompanied by a motivation to conserve, which may be provided by other instruments like financial incentives, goal setting or personal commitment (Vasiljevska et al., 2016). Smart meters can be considered as the interface between the consumers and the energy utilities and they enable consumer to interact with retailers through energy contracts. Energy contracts are becoming increasingly complex with different types of retail prices and degree of complexity concerning the associated technology. This represents a risk for consumers that may take the wrong decisions in the choice of energy contracts and services (Lavrijssen, 2017). To explore the complexity of this interaction (Mengolini, 2017; Vasiljevska et al., 2016) have developed an agentbased model that analyses the diffusion patterns of energy services (represented by energy contracts) and associated switching rate among contracts. Figure. 2 illustrates in a simplified way the interactions between the social actors and the electricity infrastructure. In Fig. 2 the consumer interacts with the electricity supplier and with the social network (community). The electricity supplier communicates with the consumer through electricity contracts, each characterized by a different type of end-user service defined in the contract and enabled by smart metering. Based on the information included in the contracts (linked to the kind of service offered, e.g.: indirect feedback, time of use pricing, home automation, ...) and the interaction with the social network, the consumer will adapt and change its behaviour. The behavioural change will have an impact on the social actors and on the electricity network (social outcomes) (Vasiljevska et al., 2016). In this simplified representation of (a part of) the electricity system we can identify the three social dimensions of the socio-energy approach proposed.

Social process: institutional decisions to roll out smart meters, consumer's decision to adopt the infrastructure (voluntary or compulsory), consumer's choice of energy contracts, consumer's interaction with the social network;

Social change: consumer's acceptance of smart meters, consumer understanding of the value of the technology, consumer's behavioural change through peer interaction;

Social outcomes: consumer's achievement of own goals (financial, comfort, environmental) creates benefit for electricity network management, but can also create or reinforce existing inequalities.

The example highlights how the technology-centric view of the energy system is framed around the average consumer or early-adopter, leaving vulnerable groups and those living in energy poverty underrepresented (Rowlands \& Stephen, 2016). 


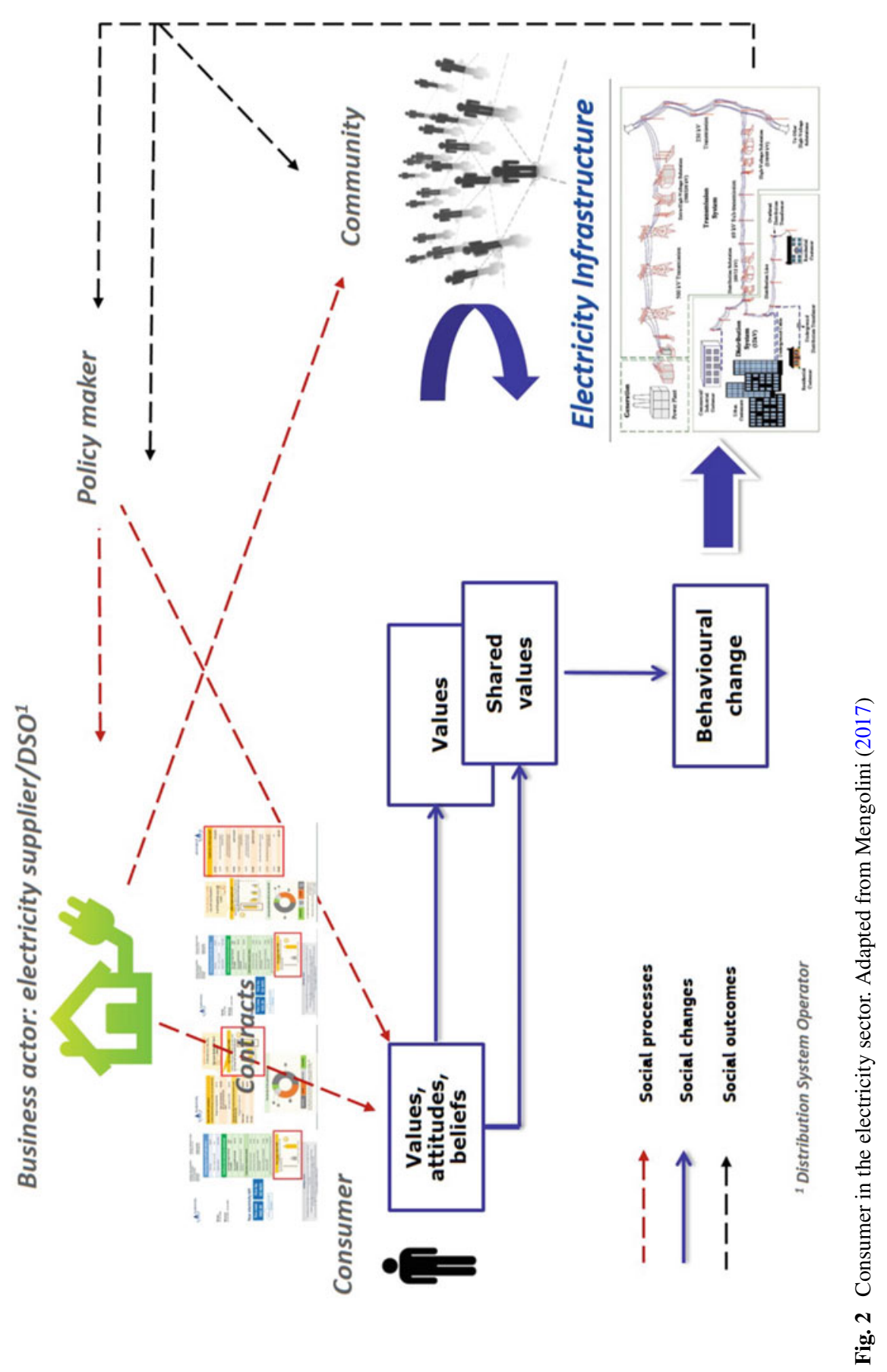


Wider societal implications are not at the forefront of initial considerations. The focus is mainly on technology and how it can positively transform the conditions of the average consumer. The smart home discourse revolves around "the stereotypical nuclear family in a neighbourhood of detached homes full of modern conveniences" ((Rowlands \& Stephen, 2016, p. 8). The government incentive schemes designed to stimulate a greener, climate friendly energy system, may have a significant distributional effect in terms of income transfer from all taxpayers to a relatively privileged segment of the population.

If we take into consideration the vulnerable households that may be at risk of energy poverty, time of use pricing (which is one of the options offered in the contracts) could pose numerous problems for social housing occupants who may be less able than the average person to adapt to time-of-use pricing without potential damage to health and welfare. Another problem is that present arrangements concerning social assistance payments and rent subsidies do not recognize the potential adverse impacts of time-of-use pricing (Gilbert, 2006).

While the current view represents a shift from the techno-centric discourse since it includes the consumer, it does, however, not question how digital technologies will impact the society at large (governance). What does this representation say about the vulnerable consumers? What does it say on issues of energy poverty? The COVID 19 crisis has demonstrated the critical role of energy in daily lives where energy deprivation means being unable to engage with society, socially, economically and politically. While factors leading to energy poverty are multiple (low incomes, high bills, bad quality of houses), the pandemic amplifies the need to understand energy poverty better (ENGAGER, 2020) and calls for a wider appreciation of the social outcomes of the energy transition.

The deficiencies of the present view of the energy system are also reflected in the EU R\&I effort for smart electrification. A recent analysis of EU R\&I projects (Gangale \& Mengolini, 2019) that test approaches to fighting energy poverty suggests that the growing interest in energy poverty at policy level has not yet been reflected in the research and innovation initiatives carried out with EU financial support. Many projects analysed in the report pursue multiple objectives, such as contributing to the EU energy and climate targets and alleviating energy poverty. Such objectives complement each other but often compete for priority and resources. The report suggests that more projects with a clearer focus on energy poverty and vulnerable consumers and on the wider societal aspects of the energy transition, would help to improve understanding of this phenomenon and to identify effective solutions to address it. Another interesting observation that emerges from this recent analysis and that is relevant for a socio-energy perspective is that for projects tackling energy poverty, results calculated in terms of energy or cost savings are not always a good measure of the success of the initiative. In local situations of high energy poverty, households can decide to reinvest part of the savings into higher living comfort. In these cases, the unchanged or even higher energy consumption reported after the implementation of the project activities is a sign that the project was successful in mitigating energy poverty. Future research should investigate other indicators to measure the success of the initiative, tailored to different segments of the vulnerable 
consumers' population (e.g. increased comfort of living, health and well-being, added market value of the property, etc.). The difficulty of shifting from a technology-centric view to a socio-energy framework clearly emerges from this analysis.

\section{Concluding Remarks}

This chapter has presented the evolution of the EU energy policy and other EU initiatives related to energy, showing how the concepts of inclusiveness and justice in the energy transition have been progressively included in relevant energy policy documents. However, the translation of these concepts into concrete actions is challenging and not yet reflected in practice. This challenge also emerges from the analysis of recent research and innovation projects in the field of energy digitalization. As a tool to address this challenge, this chapter has presented a socio-energy system approach to the energy transition. This approach allows the identification of aspects that in general go unrecognized in other analytical approaches that focus mainly on the technological side. The socio-energy system approach is applied to smart metering technologies that are viewed by EU legislation as key enablers for realising the full potential of renewable energy integration and for the active involvement of consumers and communities in the energy transition. The implementation of a socio-energy approach helps in understanding how the technology-centric view of the energy system (in the present case, smart metering deployment) is framed around the average consumer or early-adopter, leaving vulnerable groups and those living in energy poverty underrepresented. A socio-energy approach also challenges the predominant use of purely quantitative results such as energy or cost savings to judge the successfulness of initiatives tackling inclusiveness and fairness (e.g. energy poverty). Social outcomes of energy policy choices and technology arrangements need to be better investigated and should be accompanied by innovative ways to measure their success. The proposed socio-energy approach offers a way of including wider societal implications of the energy transition in the design of energy policies and in their implementation. 


\section{References}

BMWI. (2017). Renewable energy sources. Retrieved from BMWI: https://www.bmwi.de/Redakt ion/EN/Dossier/renewable-energy.html

BMWI-BMU. (2010). Energy concept for an environmentally sound, reliable and affordable energy supply. Federal Ministry of Economics and Technology

Brisbois, M. C. (2020). Decentralised energy, decentralised accountability? Lessons on how to govern decentralised electricity transitions from multi-level natural resource governance. Global Transitions, 16-25.

Bugden, D., \& Stedman, R. (2019). A synthetic view of acceptance and engagement with smart meters in the United States. Energy Research \& Social Science, 137-145.

$\operatorname{COM}(2007)$ 1. (2007). An energy policy for Europe. Communication from the Commission to the European Council and the European Parliament. European Commission.

$\operatorname{COM}(2015)$ 339. (2015). Delivering a new deal for energy consumers. Communication from the Commission to the European Parliament, the Council, the European Economic and Social Committee and the Committee of the Regions. European Commission.

$\operatorname{COM}(2015)$ 80. (2015). Energy union package. A framework strategy for a resilient energy union with a forward-looking climate change policy. Communication from the Commission to the European Parliament, the Council, th European Economic and Social Committee anad the Committee of the Regions and the European Investment Bank. European Commission.

$\operatorname{COM}(2016)$ 860. (2016). Clean energy for all Europeans. Communication from the Commission to the European Parliament, the Council, the European Economic and Social Committee, the Committee of the Regions and the European Investment Bank. European Commission.

$\operatorname{COM}(2017)$ 206. (2017). Reflection paper on the social dimension of Europe. European Commission.

$\operatorname{COM}(2019)$ 175. (2019). Fourth report on the State of the Energy Union. Report from the Commission to the European Parliamanet. European Commission.

$\operatorname{COM}(2019)$ 640. (2019). The European green deal. Communication from the Commision. European Commission.

COM(2019)22. (2019). Towards a sustainable Europe by 2030. European Commission.

$\operatorname{COM}(2020)$ 456. (2020). Europe's moment: Repair and prepare for the next generation. Communication from the Commission to the European Parliament, the Council, the European Economic and Social Committee and the Committee of the Regions. European Commission.

$\operatorname{COM}(2020)$ 67. (2020). Shaping Europe's digital future. Communication from the Commission to the European Parliament, the Council, the European Economic and Social Committee and the Committee of the Regions. European Commission.

Council of European Energy Regulators. (2019). Regulatory aspects of self-consumption and energy communities. CEER.

Cseres, K. (2018). The active energy consumers in EU law. European Journal of Risk Regulation, 227-244.

Devine-Wright, P. (2007). Energy citizenship: Psychological aspects of evolution in sustainable energy technologies. In J. Murphy (Ed.), Governing technology for sustainability. Routledge.

Directive (EU) 2018/2001. (2018). Promotion of the use of energy from renewable sources, European Parliament and Council of the European Union. Official Journal of the European Union, L 328.

Directive (EU) 2018/2002. (2018). Amending directive 2012/27/EU on energy efficiency. Officila Journal of the European Union, L328.

Directive (EU) 2018/844. (2018). Amending Directive 2010/31/EU on the energy performance of buildings and Directive 2012/27/EU on energy efficiency. The European Parliament and the Council. Official Journal of the European Union, L156.

Directive (EU) 2019/944. (2019). Common rules for the internal market for electricity and amending Directive 2012/27/EU. European Parliament and Council of the European Union. Official Journal of the European Union, L 158. 
Directive 2009/28/EC. (2009). On the promotion of the use of energy from renewable sources and amending and subsequently repealing Directives 2001/77/EC and 2003/30/EC. The European Parliament and the Council. Offical Journal of the European, L140.

Directive 2009/72/EC. (2009). Concerning common rules for the internal market in electricity and repealing Directive 2003/54/EC. The European Parliament and the Council. Official Journal of the European Union, L211.

Directive 96/92/EC. (1996). Common rules for the internal market in electricity. The European Parliament and the Council. Official Journal of the European Communities.

Directive 98/30/EC. (1998). Common rules for the internal market in natural gas. The European Parliament and the Council. Official Journal of the European Communities.

Ecologic Institute. (2016). Understanding the energy transition in Germany. https://www.ecologic. $\mathrm{eu} / 13857$

ENGAGER. (2020). European energy poverty: Agenda co-creation and knowledge innovation. Energy Poverty Action. Call for Action.

ENLARGE. (2018). Report on participatory approaches in sustainable energy emerging from 'real life' practices. https://www.enlarge-project.eu/wp-content/uploads/2018/11/D_2_1_2018_ 01_24.pdf

European Union. (2012). Charter of fundamental rights of the European Union. Official Journal of the European Union. European Union.

European Union. (2017). European pillar of social rights. European Union.

Frederiks, E. R., Stenner, K., \& Hobman, E. V. (2015). Household energy use: Applying behavioural economics to understand consumer decision-making and behaviour. Renewable and Sustainable Energy Reviews, 1385-1394.

Gangale, F., \& Mengolini, A. (2019). Energy poverty through the lens of EU research and innovation projects. Publication Office of the European Union.

Gangale, F., Mengolini, A., \& Onyeji, I. (2013). Consumer engagement: An insight from smart grid projects in Europe. Energy Policy, 621-628.

Gangale, F., Mengolini, A., Marinopoulos , A., \& Vasiljevska, J. (2020). Collective actions in energy: An insight for EU reseach and innovation projects. Publication office of the European Union.

Gangale, F., Vasiljevska, J., Covrig, C., Mengolini, A., \& Fulli, G. (2017). Smart grid projects outlook 2017. Facts, figures and trends in Europe, EUR 28614. Publication Office of the European Union.

Gilbert, R. (2006). Electricity metering and social housing in Ontario. Social Housing Services Corporation.

Halbe, J., Holtz, G., \& Ruutu, S. (2020). Participatory modeling for transition governance: Linking methods to process phases. Environmental Innovation and Societal Transitions, 60-76.

IEA. (2017). Digitalization \& energy. International Energy Agency.

IEA. (2020). European Union 2020. Energy Policy Review.

Jenkins, K., McCauley, D., Heffron, R., Stephan, H., \& Rehner, R. (2016). Energy justice: A conceptual review. Energy Research \& Social Science, 174-182.

Lavrijssen, S. (2014). The different faces of the energy consumers. Journal of Competition Law and Economics, 257-292.

Lavrijssen, S. (2017). Power to the energy consumers. European Energy and Environmental Law Review, 172-187.

Mengolini, A. (2017). Prosumer behaviour in emerging energy systems. Politecnico di Torino.

Mengolini, A., Gangale, F., \& Vasiljevska, J. (2016). Exploring community-oriented approaches in demand side management projects in Europe. Sustainability, 8(12).

Micklitz, H.-W., Reisch, L., \& Hagen, K. (2011). An introduction to the special issue on "behavioural economics, consumer policy, and consumer law". Journal of Consumer Policy, 271-276.

Miller, C., Iles, A., \& Jones, C. (2013). The social dimensions of energy transitions. Science as Culture, 135-148. 
Miller, C., Richter, J., \& O’Leary, J. (2015). Socio-energy systems design: A policy framework for energy transitions. Energy Research \& Social Sciences, 29-40.

Mundaca, L., Busch, H., \& Schwer, S. (2018). 'Successful' low-carbon energy transitions at the community level? An energy justice perspective. Applied Energy, 292-303.

Regulation (EC) No. 713/2009. (2009). Establishing an agency for the cooperation of energy regulators. The European Union and the Council. Brussels: Official Journal of the European Union, L211.

Regulation (EC) No. 714/2009. (2009). On conditions for access to the network for cross-border exchanges in electricity and repealing Regulation (EC) No. 1228/2003. The European Parliament and the Council. Official Journal of the European Union, L211.

Regulation (EC) No. 715/2009 . (2009). On conditions for access to the natural gas transmission networks and repealing Regulation (EC) No. 1775/2005. The European Parliament and the Council. Official Journal of the European Union, L211.

Regulation (EU) 2018/1999. (2018). Governance of the Energy Union. The European Parliament and the Council, The European Union and the Council. Official Journal of the European Union, L328.

Regulation (EU) 2019/941. (2019). On risk-preparedness in the electricity sector and repealing Directive 2005/89/EC. The European Parliament and the Council. Official Journal of the Europea Union, L158.

Regulation (EU) 2019/942. (2019). Establishing a European Union Agency for the Cooperation of Energy Regulators. Official Journal of the European Union, L158.

Regulation (EU) 2019/943. (2019). On the internal market for electricity. The European Parliament and the Council. Official Journal of the European Union, 158.

Rowlands, I., \& Stephen, G. (2016). Vulnerable households and the smart Grid ontario. Metcalf Foundation.

SEC(2010) 1407. (2010). An energy policy for consumers. Commission Staff Working Paper. European Commission.

Steffen, B., Egli, F., Pahle, M., \& Schmidt, T. (2020). Navigating the clean energy transition in the COVID-19 Crisis. Joule.

Steg, L., Perlaviciute, G., \& Van der Werff, E. (2015). Understanding the human dimensions of a sustainable energy transition. Frontiers in Psychology, 6(805).

Steg, L., Shwom, R., \& Dietz, T. (2018). What drives energy consumers? Engaging people in a sustainable energy transition. IEEE Power and Energy Magazine, 16(1), 20-28.

Strand, R., Kovacic, Z., Funtowicz, S., Benini, L., \& Jesus, A. (2021). Growth without economic growth. European Environmental Agency.

TFEU. $(2012,1026)$. Consolidated version of the treaty on the functioning of the European Union. Official Journal of the European Union C326.

van Veelen, B., \& van der Horst, D. (2018). What is energy democracy? Connectin social science energy research and political theory. Energy Research \& Social Sciences, 19-28.

Vasiljevska, J., Douw, J., Mengolini, A., \& Nikolic, I. (2016). An agent-based model of electricity consumer. Journal of Artificial Societies and Social Simulation.

Vesnic-Alujevic, L., Breitegger, M., \& Guimaraes Pereira, A. (2016). What smart grids tell about innovation narratives in the European Union: Hopes, imaginaries and policy. Energy Research \& Social Sciences, 16-26.

Veuma, K., \& Bauknecht, D. (2019). How to reach the EU renewables target by 2030? An analysis of the governance framework. Energy Policy, 299-307.

Vitéz, B., \& Lavrijssen, S. (2020). The energy transition: Democracy, justice and good regulation of the heat market. Energies, 13(5), 1088. 
Open Access This chapter is licensed under the terms of the Creative Commons Attribution 4.0 International License (http://creativecommons.org/licenses/by/4.0/), which permits use, sharing, adaptation, distribution and reproduction in any medium or format, as long as you give appropriate credit to the original author(s) and the source, provide a link to the Creative Commons license and indicate if changes were made.

The images or other third party material in this chapter are included in the chapter's Creative Commons license, unless indicated otherwise in a credit line to the material. If material is not included in the chapter's Creative Commons license and your intended use is not permitted by statutory regulation or exceeds the permitted use, you will need to obtain permission directly from the copyright holder.

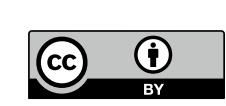

